University of Louisville

ThinkIR: The University of Louisville's Institutional Repository

$10-1944$

\title{
The development of ethyl cellulose lacquers for automotive use : an ethyl cellulose lacquer for coating plastics.
}

Robert Carlton Krueger

University of Louisville

Follow this and additional works at: https://ir.library.louisville.edu/etd

Part of the Chemical Engineering Commons

\section{Recommended Citation}

Krueger, Robert Carlton, "The development of ethyl cellulose lacquers for automotive use : an ethyl cellulose lacquer for coating plastics." (1944). Electronic Theses and Dissertations. Paper 1994. https://doi.org/10.18297/etd/1994

This Master's Thesis is brought to you for free and open access by ThinkIR: The University of Louisville's Institutional Repository. It has been accepted for inclusion in Electronic Theses and Dissertations by an authorized administrator of ThinkIR: The University of Louisville's Institutional Repository. This title appears here courtesy of the author, who has retained all other copyrights. For more information, please contact thinkir@louisville.edu. 


\title{
UNIVERSITY OF LOUISVIIIE
}

THE DEVRLOPMENT OF ETHYI CELIULOSE LACQUERS

FOR AUTOMOTIVE USE

AN ETHYI CELLULOSE IACQUER FOR COATING PLASTICS

\author{
A Thesis \\ Submitted to the Faculty \\ of the Graduate School \\ of the University of Louisville \\ in Partial Fulfillment \\ of the Requirements \\ for the Degree of
}

MASTER OF CHEMICAI ENGINEERING

Department of Chemical Engineering

Robert Carlton Krueger

October 1944 
THE DEVELOPNENT OF ETHYI CELIULOSE LACQUERS FOR AUTOMOTIVE USE AN ETHYI CELLULOSE IACQUER FOR COATING PIASTICS

Robert Carlton Krueger Approved by Examining Committee: Director R. C. Ernst

October 1944 
TABIE OF CONTENTS

List of Tables $\ldots \ldots \ldots \ldots \ldots \ldots \ldots \ldots \ldots \ldots \ldots \ldots \ldots$ iv Acknowledgment $\ldots \ldots \ldots \ldots \ldots \ldots \ldots \ldots \ldots \ldots \ldots \ldots \ldots \ldots \ldots \ldots \ldots$ v

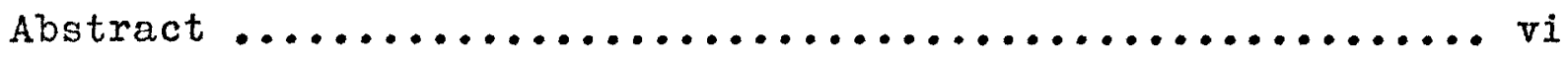
General Historical $\ldots \ldots \ldots \ldots \ldots \ldots \ldots \ldots \ldots \ldots \ldots \ldots \ldots \ldots$ Theoretical ................................. The Development of Ethyl Cellulose Lacquers for Automotive Use .......7 7

Introduction $\ldots \ldots \ldots \ldots \ldots \ldots \ldots \ldots \ldots \ldots \ldots \ldots . \ldots . \ldots$

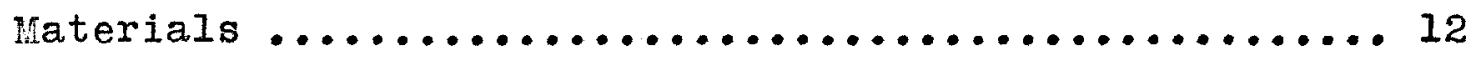

Preparation of Pigmented Lacquers .............. 15

Preparation of Panels ...................... 19

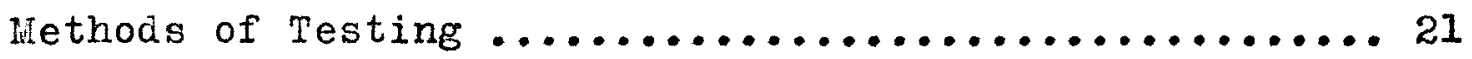

Data and Results with Interpretation ............. 23

Conclusions and Recommendations ...............28 An Ithyl Cellulose Lacquer for Coating Plastics ......... 30

Introduction $\ldots \ldots \ldots \ldots \ldots \ldots \ldots \ldots \ldots \ldots \ldots \ldots \ldots$

Materials ............................... 33

Preparation of Pigmented Lacquers ............... 35

Data and Results with Interpretation ................. 37

Conclusions and Recommendations ...............44

Literature Cited .......................... 45

Acknowledgments $\ldots \ldots \ldots \ldots \ldots \ldots \ldots \ldots \ldots \ldots \ldots \ldots \ldots$ 


\section{IIST OF TABIES}

Table

Title

Page

I Composition of \#62 Black Ethocel Lacquer ....... 10

II Composition of \#62 Gray Sanding surfacer ....... 11

II Change in Chip Composition Before and

$$
\text { After Milling ... } 17
$$

IV Composition of Colored Lacquers ................

$V$ Comparison of Nitrocellulose and Fthyl

$$
\text { Cellulose for Water Soak ... } 24
$$

VI Results of Cold-Check Test ................. 26

VII Plastic Lacquer Formulations .............. 38

VII Results of Weatherometer Test ..............40 


\section{ACKNOWIEDGNENT}

The author wishes to acknowledge the kind assistance and helpful guidance of Dr. R. C. Ernst, who directed this research. 
ABSTRACT

There have been developed various colored ethyl cellulose lacquers that compare favorably with standard nitrocellulose lacquers in physical tests. Ultra violet light caused rather pronounced darkening of the lighter colors such as white and light yellow, probably because of the use of high amounts of phenolic resin. Also because of the presence of relatively large amounts of phenolic resin, the cost was somewhat higher than a comparable nitrocellulose lacquer. Suggestions for further work and improvement are included. An ethyl cellulose lacquer has also been developed to be applied by spray or brush to ethyl cellulose plastics with a minimum amount of deleterious effects such as warping and decreasing of flexibility. Good color and gloss were obtained by use of proper resin combinations. With low ethyl cellulose content it was found necessary to clean the plastic surface mechanically because the remaining traces of die lubricant were apparently incompatible with the lacquer and caused subsequent flatting action and loss of gloss of the lacquer. 
GENERAI HISTORICAL

Probably one of the first descriptions of ethyl cellulose and methods for its preparation appeared in 1905 in the Monatshefte $\mathrm{für}_{\mathrm{r}}$ Chemie by Suida (12). Leuchs (9), Lilienfeld (10), and Dreyfus (5), and many others obtained patents on the preparation of the ether. Denham (2) and his co-workers had shown also that the cellulose ethers may be formed by the substitution of an alkyl or aryl radical in place of a hydroxyl hydrogen atom in cellulose. The high cost of manufacture at that time overcame the many industrial possibilities that were indicated at that time.

Until 1936, all ethyl cellulose used in the United States was imported, but now commercial ethyl cellulose made by American manufacturers is on the market at a lower cost than the imported material.

The manufacture of ethyl cellulose $(7,8)$ follows the clasical methods for the preparation of cellulose ethers. Cellulose from any desired source such as cotton or wood is converted into alkali cellulose by treatment with a strong aqueous solution of sodium hydroxide. This alkali cellulose is then alkylated with such reagents ethyl chloride or sulfate.

The temperature at which this alkylation is to be carried out must be controlled to prevent any undesirable 
degradation or destruction, either of the cellulose or of the alkylating agent. After the etherification is complete the excess reagents and the by-products of the reaction are remored by washing and distillation. The purification of ethyl cellulose is a simple operation consisting essentially of washing the product free of soluble materials.

The properties of ethyl cellulose $(7,8,13)$, like those of other cellulose derivatives, depend primarily upon the degree to which the cellulose has been etherified. It is customary to consider the cellulose molecule as composed of glucose residues, each of which has three hydroxyl groups available for etherification. The ethyl cellulose of commerce has less than three of the available hydroxyl groups etherified.

The effects of variation in the degree of ethylation are very pronounced with respect to the solubility of the product in water and organic solvents, and with respect to the melting point or softening point of the ether. Solubility in both polar and non-polar organic solvents is best with ethyl cellulose with 47-49.5\% ethoxy content, corresponding to 2.4 to 2.58 hydroxyl groups etherified per gluose residue. The commercial ethyl cellulose having this degree of substitution combines the widest variety of useful properties. Ethyl cellulose is a white solid resembling cellulose acetate in its flame resistance and resembling nitrocellulose in its compatibility with other film forming ingredients. 
Ethyl cellulose is more resistant to acids and alkalies and to discoloration by sunlight than the other esters of cellulose (13). Fthyl cellulose shows the widest solubility of any commercially available film forming material $(3,7,13)$. Films of ethyl cellulose exhibit a greater flexibility and toughness than the other compounds of cellulose and retain their flexibility at temperatures as low as $-40^{\circ} \mathrm{C}$. $(3,7,13)$.

Even in low percentages, ethyl cellulose adds a remarkable degree of flexibility to hard resins, both natural and synthetic. The compatibility of ethyl cellulose more closely resembles that of nitro-cellulose than that of cellulose acetate. Ethyl cellulose differs from nitro-cellulose in that it does not show so wide a compatibility with alkyd resins, in particular the unmodified and short oil length alkyds $(3,7,13)$. The tolerance of ethyl cellulose for many incompatible resins can be greatly improved by incorporating a third ingredient which is a good mutual solvent for both the ethyl cellulose and the compatible resin ( 8 ). 
THEORETICAI

A lacquer can best be defined by considering the nature and purpose of its various components. Lacquers have rolatile and non-rolatile constituents; the rolatile constituents being suitable solvents, the non-volatile constituents consisting of resins, plastcizers, and sometimes pigment.

The non-volatile portion of a lacquer is the filmforming constituent, whereas the volatile portion or solvent is present to facilitate the application of the non-volatile material in a smooth, unbroken film of uniform thickness. Hardening and film formation in lacquers are due primarily to solvent eraporation and to a much lesser extent the oxidation and polymerization of any oxidizing alkyds or similar materials that may be present. The greater the relative amount of ethyl cellulose the faster the dry is and the greater the toughness. The limiting factors are the viscosity non-volatile ratio, and the cost. Both viscosity and cost will increase with increasing amounts of ethyl cellulose. The greater the amount of hard resin the better the gloss, the shorter the film, and usually the lower the cost. Plasticizers, either chemical or resin type, are used to increase the flexibility of the hard resins and to a lesser extent that of the ethyl cellulose. Pigments are used primarily for decorative results, i.e. color. They are 
also used for physical effects as filling of pits, flatting of gloss, apparent increase of adhesion, improved corrosion resistance, etc.

The various resins, plasticizers, and solvents may be blended by agitation of the mass and thus incorporating it into a homogeneous solution. The dispersion of pigment in lacquer is somewhat more involved.

The problem of dispersion is one in reduction of the pigment agglomerates. This dispersion is best accomplished under high shear stress with sufficient vehicle present to coat the pigment particles to prevent reagglomerization.

Various methods (1I) are available for the dispersion of pigments. Among these are pebble mills, steel ball mills, 1, 2, 3, 4, or 5-roll mills, Banbury mills, BakerPerkins, and Bramley mills.

Each method has its advantages and disadrantages, and has a particular place where it is most efficient and best suited. A complete discussion of this subject would be lengthy and beyond the scope of this paper. It will suffice to say that the method in use in the industry where a high gloss is desired with a thermoplastic resin such as ethyl cellulose is the dispersion under heat and high percent non-rolatile by means of a Baker-Perkins unit, a Banbury with subsequent sheeting on a 2-roll mill, or the use of the 2-roll by itself. The results of the last two methods of dispersion are fairly 
hard chips that are dissolved in the lacquer solution or dissolved at the same time as the rest of the ingredients are being cut into solution.

If the resultant lacquer is not of the desired viscosity for correct application, a reduction of visosity can be obtained by the addition of more solvents or thinners. Normally a lacquer is of high viscosity to lessen if not eliminate the settling of pigment and also to lower the cost of transportation of thinner which is usually purchased at a closer source. 
THE DEVELOPHENT OF ETHYI CELIULOSE IACQUERS FOR AUTOMOTIVE USE 


\section{INTRODUCT ION}

Both nitrocellulose lacquers and alkyd enamels are widely used for automotive finishing and refinishing systems. Even the fastest drying of the alkyds are much slower in drying than nitrocellulose lacquers, and therefore it is more difficult to prevent dust that is floating in the air from sticking to the wet surface and marring the finish. Moreover, the speeding up of air drying alkyds is frequently associated with poor durability.

An ethyl cellulose lacquer is comparable to nitrocellulose types and has the advantage of much better flame stability, the use of cheaper and weaker solvents, and a far less tendency to "Iift" undercoats because of the weaker solvents that are permitted.

The disadvantage of ethyl cellulose is its softness and its incompatibility with a large number of resins that impart strength to the film.

Because of the excellent results with the \#62 Black Tthocel Iacquer and \#62 Gray Sanding Surfacer developed by Ernst (6), it was decided to try the incorporation of various colored pigments in the topcoat. It was proposed that the following pigments be selected because of their present use in the industry: (a) Phthalocyanine Blue, (b) Toluidine Red, (c) Chrome Yellow, (d) Iron BIue, (e) Chrome Green, (f) Ferrite 
Yellow, (g) Ferrite Red, and (H) Titanium Dioxide.

Ethyl cellulose lacquers with these pigments should

then be checked against standard nitrocellulose lacquers for the usual tests for automotive lacquer such as weathering, cold checking, water resistance, and flexibility.

The composition by weight of the \#62 Black Ethocel

Lacquer and of the \#62 Gray Sanding Surfacer (6) are shown in tables $I$ and $I I$. 


\section{TABIE I}

COMPOSITION OF \#62 BIACK ETHOCEL LACQUER

\begin{tabular}{|c|c|c|}
\hline $\begin{array}{l}\text { lo cps. Ethyl Cellulose } \\
\text { Carbon Black } \\
\text { Ethyl Alcohol } \\
\text { Toluol }\end{array}$ & $\begin{array}{l}5.95 \% \text { RBH } \\
\text { Dispersion \#9002 }\end{array}$ & $\begin{array}{l}0.893 \% \\
0.893 \% \\
0.834 \% \\
3.33 \%\end{array}$ \\
\hline $10 \mathrm{cps}$. Ithyl Cellulose, & Standard Ethoxy & 10.6 \\
\hline Beckacite 3000 & & 11.5 \\
\hline Aroplaz 930 & & 5.7 \\
\hline Ethyl Alcohol & & 12.2 \\
\hline Toluol & & $\frac{54.05}{00.0}$ \\
\hline
\end{tabular}




\section{TABLE IT}

COHPOSITION OF \#62 GRAY SANDING SURFACER

Iithopone

China clay

Celite ON-110

Asbestine

Ethyl Cellulose Carbon Black Alcohol

Toluol $30.3 \% \mathrm{RBH}$ Dispersion \#9002

Beckacite 3000

Aroplaz 930

Ethyl Alcohol

Toluol

$$
\begin{array}{r}
11.62 \% \\
4.13 \% \\
3.34 \% \\
4.13 \% \\
4.58 \% \\
4.58 \% \\
4.24 \% \\
16.9 \% \\
8.65 \% \\
4.32 \% \\
4.83 \% \\
24.21 \%
\end{array}
$$

PEBBIF YILI GRIND

10 cps. Ethyl Cellulose, Standard Ethoxy $\frac{4.47}{100.0} \%$ 


\section{MATERIALS}

The materials used in this portion of the investigation were steel panels, various colored pigments, ethyl cellulose, phenolic resin, alkyd plasticizer, solvents, and the competitive nitrocellulose lacquers.

The unmodified phenolic resin Beckacite 3000 and the non-drying alkyd plasticizer were used because of the highly successful results obtained in the \#62 Black Ethocel Iacquer developed by Ernst (6) and his co-workers in the same problem. The pigments that were used covered a wide field in chemical composition and by suitable blends or mixes of these pigments practically the whole range of desired automotive colors could be obtained. No claim is made that the best of each type of pigment was used so that improvement from this point should be considered.

The properties of the materials are listed below: Steel Fanels - These were $5^{\prime \prime} \times 10^{\prime \prime}$ cold rolled 20 gauge automotive steel.

Tthyl Cellulose - This cellulosic ether was supplied by the Dow Chemical Co. under the name Ethocel. This is of standard ethoxy content (48.5-49.5\%) and has a viscosity of 7 centipoises in a 5\% by weight solution in a solvent composed of $80 \%$ toluene and $20 \%$ ethanol. It is a white granular substance having a specific gravity of 1.13 . 
Thenolic Resin - The only resin used here was Beckacite 3000 since this was the resin used in the standard lacquer. It is an unmodified phenolic resin made by Reichhold Chemicals, Inc.

Alkyd Plasticizer - The only plasticizer used was Aroplaz 930, a non-drying alkyd made by stroock-Wittenberg, a subsidiary of United States Industrial Alcohol Co. This is a plastic that is very compatible with ethyl cellulose.

Chrome Yellow - This pigment is a light chrome yellow manufactured and sold by the Kentucky Color and Pigment Co. as their 95-7 Chrome Yellow. It has a weight per gallon of 48.4 pounds.

Chrome Green - This is a medium chrome green pigment which is also made by Kentucky Color and Pigment $\mathrm{Co}$. and is sold as their 16-H Chrome Green. It has a wieght per gallon of 37.7 pounds.

Ferrite Yellow - This is a deep ferrite sold by Binney and Smith Co. as their Ferrite Orange. Weight per gallon is 33.32 pounds.

Ferrite Red - This is Geo. Hepham Company's \#527 Red Oxide. It is a precipitated oxide weighing 42.48 pounds per gallon.

Titanium Dioxide - A rutile type, unreduced titanium pigment sold and distributed as RT-110 by the Krebs Pigment Co., subsidiary of dupont de Nemours and Co. It has a weight per gallon of 34.99 pounds. 
Iron Blue - This is a conventional chinese blue sold as B-63D by $\mathrm{Krebs}$ Pigment Company. It has a bulking value of 14.66 pounds per gallon.

Lamplack - R. T. Vanderbilts $P-33$ was used and has a weight per galion of 14.90 pounds.

Carbon Black - Godfrey I. Cabot Company's \#7I was used weighing 14.58 pounds per gallon.

Toluidine Red - A light toluidine was used that is made by Kentucky Chemical and Color Co. and known as \#1077. It has a weight per gallon of 11.6 pounds. RBH Dispersion \#9002 - A carbon black dispersion manufactured by R-B-H Dispersions, Inc., Bound Brook, N. J. It has a composition of $15 \%$ carbon black, $15 \%$ ethyl cellulose, $14 \%$ ethyl alcohol, and 56\% toluol.

Ethyl alcohol - A completely denatured alcohol distributed by United States Industrial Alcohol Co. as Solox 95\%. Butyl Alcohol - An industrial butanol supplied by United States Industrial Alcohol Co. Ethyl Acetate - An 85-88\%ester content material obtained from United States Industrial Alcohol Co. Butyl Acetate - An $85-88 \%$ ester content material obtained from United States Industrial Alcohol Co. Toluol - A $20^{\circ}$ toluol obtained from Koppers Co. 
PREPARATION OF PIGMENTED ILACQUERS

Pigment was dispersed by means of a steel ball mill in \#62 Ethocel Black Lacquer (6) omitting the RBH dispersion. This steel ball mill is a one-quart round glass jar partially filled with $1 / 8^{\prime \prime}$ steel shot. When charged with the desired ingredients the mill or jar is then tumbled 48-72 hours.

The per cent pigment was based on similar experience in nitrocellulose technology. No apparent difficulty was encountered in dispersing the pigments, except that it was found that the lacquer films on drying seemed to lose some gloss.

Since in both synthetic enamels and nitrocellulose lacquers, steel ball mills are second only to pebble mills for obtaining poor gloss, the evident approach to the improvement of gloss would be an improved grinding method. such a method would be the use of a two-roll mill. Since this was the most easily available at the time, chips were made using the desired pigments. See Table III.

In the case of the blacks and the iron blue, the addition of plasticizer (Aroplaz 930) was made necessary because of the higher oil absorption of the pigments. Because solvent is lost on the hot rolls, the composition is different after milling from the initial composition. From the results of many production runs of both 
ethyl cellulose and nitrocellulose the assumption is that whites are $98 \%$ non-volatile, blue and black chips are $92 \%$, and other colors are 95\% non-volatile. These figures, of course, will vary with the solvent used and with the time and temperature of milling.

Chips are then tumbled with the desired amounts of the remaining requisite constituents until solution is effected, usually twelve hours are sufficient. Composition of the resultant ethyl cellulose lacquers is shown in Table IV. Neither the lampblack nor the carbon black was well dispersed; hence the \#62 Black Ethocel Lacquer made with RBH dispersion was used. The toluidine red had low gloss and was quite chalky. It is quite evident that further work with these pigments is indicated. They were not included in the subsequent tests. 
TABLE III

CHANGE IN CHIP CONPOSITION BEFORE AND AFTER MILLING

\begin{tabular}{|c|c|c|c|c|c|c|c|c|c|}
\hline \multicolumn{6}{|c|}{ Before billing (Actual) } & \multicolumn{4}{|c|}{ After Milling (Calculated)** } \\
\hline Pigment & Manufacturer & $\begin{array}{c}\% \\
\text { Pigment } \\
\end{array}$ & $\% E / C^{*}$ & $\begin{array}{c}\% \text { Aroplaz } \\
930\end{array}$ & $\begin{array}{c}\% \\
\text { Butanol } \\
\end{array}$ & $\begin{array}{c}\% \\
\text { Pigment }\end{array}$ & $\% \mathrm{E} / \mathrm{C}$ & \begin{tabular}{rr|}
$\%$ & aro- \\
plaz & 930 \\
\end{tabular} & $\begin{array}{c}\% \\
\text { Butanol } \\
\end{array}$ \\
\hline $\begin{array}{l}\text { Lt. Chrome } \\
\text { Yellow }\end{array}$ & $\begin{array}{l}\mathrm{Ky} \cdot \mathrm{Col} \text { lor } \& \\
\text { Chem.Co. } 95-7\end{array}$ & 53.3 & 38.7 & - & 8.0 & 55.0 & 40.0 & - & 5.0 \\
\hline $\begin{array}{l}\text { Wed. Chrome } \\
\text { Green }\end{array}$ & $\begin{array}{l}\text { Ky.Color \& } \\
\text { Chem.Co.16-H }\end{array}$ & 53.3 & 38.7 & - & 8.0 & 55.0 & 40.0 & - & 5.0 \\
\hline $\begin{array}{l}\text { Ferrite } \\
\text { Yellow }\end{array}$ & $\begin{array}{l}\text { Binney \& Smith } \\
\text { Ferrite Orangl }\end{array}$ & 53.3 & 38.7 & $=$ & 8.0 & 55.0 & 40.0 & $=$ & 5.0 \\
\hline $\begin{array}{c}\text { Ferrite } \\
\text { Red }\end{array}$ & $\begin{array}{l}\text { Wepham's } \\
\text { it527 }\end{array}$ & 53.3 & 38.7 & $=$ & 8.0 & 55.0 & 40.0 & $=$ & 5.0 \\
\hline $\begin{array}{l}\text { Titonium } \\
\text { Dioxide }\end{array}$ & $\begin{array}{r}\text { Krebs } \\
R F-110 \\
\end{array}$ & 53.3 & 38.7 & $=$ & 8.0 & 56.7 & 41.3 & $=$ & 2.0 \\
\hline Iron BIue & $\begin{array}{l}\mathrm{Krebs} \\
\mathrm{B}-63 \mathrm{D} \\
\end{array}$ & 36.7 & 36.7 & 11.6 & 15.0 & 39.7 & 39.7 & 12.6 & 8.0 \\
\hline Lamp Black & $\begin{array}{l}\text { Vanderbolt } \\
\mathrm{P}-33\end{array}$ & 34.8 & 34.8 & 17.4 & 13.0 & 36.8 & 36.8 & 18.4 & 8.0 \\
\hline $\begin{array}{l}\text { Carbon } \\
\text { Black }\end{array}$ & $\begin{array}{l}\text { Cabot's } \\
\text { Monarch if } 71\end{array}$ & 34.8 & 34.8 & 17.4 & 13.0 & 36.8 & 36.8 & 18.4 & 8.0 \\
\hline $\begin{array}{l}\text { Toluidine } \\
\text { Red }\end{array}$ & $\begin{array}{l}\text { Ky.Color \& } \\
\text { Chem.Co. }\end{array}$ & 53.3 & 38.7 & - & 8.0 & 55.0 & 40.0 & - & 5.0 \\
\hline
\end{tabular}

* Ethyl Celluloso

* * Per As sumption given on page 15. 
TABLE IV

CONPOSITION OF COLORED LACQUERS

\begin{tabular}{|c|c|c|c|c|c|c|c|c|}
\hline Lacquer & $\% \mathrm{E} / \mathrm{C*}$ & $\begin{array}{l}\% \text { Beckosol } \\
3000 \\
\end{array}$ & $\begin{array}{l}\% \text { Aroplaz } \\
930\end{array}$ & $\%$ Pigment & $\%$ Butanol & $\%$ Ethanol & $\%$ Toluene & $\% \mathrm{~N} \cdot \mathrm{V}_{0} * *$ \\
\hline $\begin{array}{l}\text { Lt. Chrome } \\
\text { Yellow }\end{array}$ & 11.5 & 7.8 & 7.8 & 7.5 & 2.0 & 6.5 & 56.9 & 34.6 \\
\hline $\begin{array}{l}\text { Med. Chrome } \\
\text { Green }\end{array}$ & 11.5 & 7.8 & 7.8 & 7.5 & 2.0 & 6.5 & 56.9 & 34.6 \\
\hline $\begin{array}{l}\text { Ferrite } \\
\text { Yellow } \\
\end{array}$ & 11.5 & 7.8 & 7.8 & 7.5 & 2.0 & 6.5 & 56.9 & 34.6 \\
\hline $\begin{array}{l}\text { Ferrite } \\
\text { Red }\end{array}$ & 11.5 & 7.8 & 7.8 & 7.5 & 2.0 & 6.5 & 56.9 & 34.6 \\
\hline $\begin{array}{l}\text { Titanium } \\
\text { Dioxide }\end{array}$ & 11.5 & $7 \cdot 8$ & 7.8 & 7.5 & 2.0 & 6.5 & 56.9 & 34.6 \\
\hline Iron Blue & 11.4 & 8.1 & 7.8 & 7.3 & 2.0 & 6.5 & 56.9 & 34.6 \\
\hline $\begin{array}{c}\text { Poluidine } \\
\text { Red }\end{array}$ & 11.5 & 7.8 & 7.8 & 7.5 & 2.0 & 6.5 & 56.9 & 34.6 \\
\hline
\end{tabular}

* Ethyl Cellulose

** Non-Volatilo 


\section{PREPARATION OF PANELS}

The $5^{\prime \prime} \times 10^{\prime \prime}$ steel panels were sanded where necessary to remove rust spots, solvent washed with Solvesso \#l, (as aromatic petroleum solvent obtained from standard oil of New Jersey), and etched with a prepared phosphoric acid type cleaner. The panels were then washed well with tap water and dried by blowing with a spray gun.

The nitrocellulose panels used as a standard for comparison were built up by spraying with one coat of RinshedYlason's PNS-454 Gray Flash Sand Primer. This was lightly sanded, dusted off, and two coats of gloss lacquer applied. Iacquers used are as follows:

Black
White
Iron Blue
Chrome Yellow
Chrome Green
Red Iron Oxide

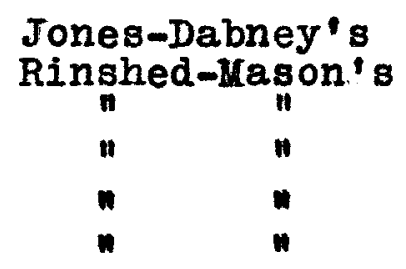
Red Iron Oxide

Reduction to spray of both primer and lacquer was 1:1 by volume with a lacquer thinner having a composition of:
Industrial Xylol
$10 \%$
Solvesso \#I
$35 \%$
N-ButanoI
$5 \%$
N-Butyl Acetate
$15 \%$
Fthanol (95\% Solox)
$10 \%$
Fthyl Acetate (85-88\% Ester) 20\% 
The ethyl cellulose panels were similarly prepared using No.62 surfacer in place of PNS-454. The surfacer was reduced 1:1 with a mixture of 20\% $\mathrm{H-Butanol,} 40 \%$ industrial xylol, and 40\% solvesso \#1. This gave a slower blend and gave good spraying results with no deleterious effect on drying time, obtaining dry to touch in 15 to 20 minutes and dry to sand in 3040 minutes.

After lightly sanding and wiping the surfacer, two coats of ethyl cellulose lacquer were then applied reducing between $2: 1$ and 1:1 (as required by viscosity of lacquer) with the same solvent used with the surfacer.

The general appearance of the ethyl cellulose films is quite farorable compared to nitrocellulose, but still it could be improved as compared to the gloss and the depth of alkyds, when no polishing is considered. 
METHOD OF TESTING

To eliminate a large quantity of panels and a needless duplication of work, one of a type of pigment was chosen. For example, the red iron oxide was used instead of both the red and yellow oxides which would react similarly. The colors tried were white (titanium dioxide), iron blue, red iron oxide, light chrome yellow, and medium chrome green, These together with the No. 62 Black Ethocel Lacquer, were compared with the standard commercial materials.

After complete drying (several days) one set of panels was subjected to a water soak test consisting of the immersion of the panels in aerated water at 105-110 F. Automotive alkyd enamels are required to hold up 96 hours without effect, nitrocellulose lacquers somewhat less.

The panels were coated on the back and edges with lacquer to prevent rusting. To eliminate any possible electrolysis effect during the test, they were hung from insulated hooks care being taken that they did not touch.

The cold check test was conducted by repeating the cycle of one hour at $140^{\circ} \mathrm{F}$ and one hour at $-30^{\circ} \mathrm{F}$. Inspection for cracking, peeling, etc., was made when the panels were removed from the cold box. To withstand $20-25$ cycles is usually considered quite satisfactory. 
The flexibility test consists of bending the panel around a 3/8" mandrel at room temperature $\left(80^{\circ} \mathrm{F}\right)$ and inspection for cracks. This is also an indication of the adhesion and elasticity.

The accelerated weathering test is run in a National Carbon Company unit. It operates at 50 rolts and 60 amperes using "Sunshine" carbons and Corex D filters" 


\section{DATA AND RESULTS WITH INTERPRETATION}

The indication is that the ethyl cellulose is somewhat better than the nitrocellulose in regard to pimpling during water soak (See Table V, pages 24 and 25). However, in some cases, notably iron blue and chrome green, and to a lesser extent chrome yellow and iron oxide, whitening of the film occurred which largely disappeared on drying. This is a definite weakness which should be improved if not entirely eliminated.

The results of the cold-check test are shown in Table VI, page 26.

The flexibility test showed the greatest difference between nitrocellulose and ethyl cellulose formulations. All the ethyl cellulose panels showed no cracking and are in excellent condition. The chrome yellow nitrocellulose shows no cracking but does show slight strains. All the other nitrocellulose films failed miserably showing extremely bad cracking and very poor adhesion.

The adhesion and length were also checked by scratching with a coin or knife. By this method the ethyl cellulose lacquers have slightly better adhesion than the nitrocellulose, but when comparing with the mandrel tests the nitrocellulose has very poor adhegion on bending.

In the accelerated weathering machine the white and 
TABLE V

COWPARISON OF INITROCELUULOSE AND ETHYLCELLULOSE FOR WTE SO.J -

AERATED TANK AT $105-110^{\circ} \mathrm{F}$

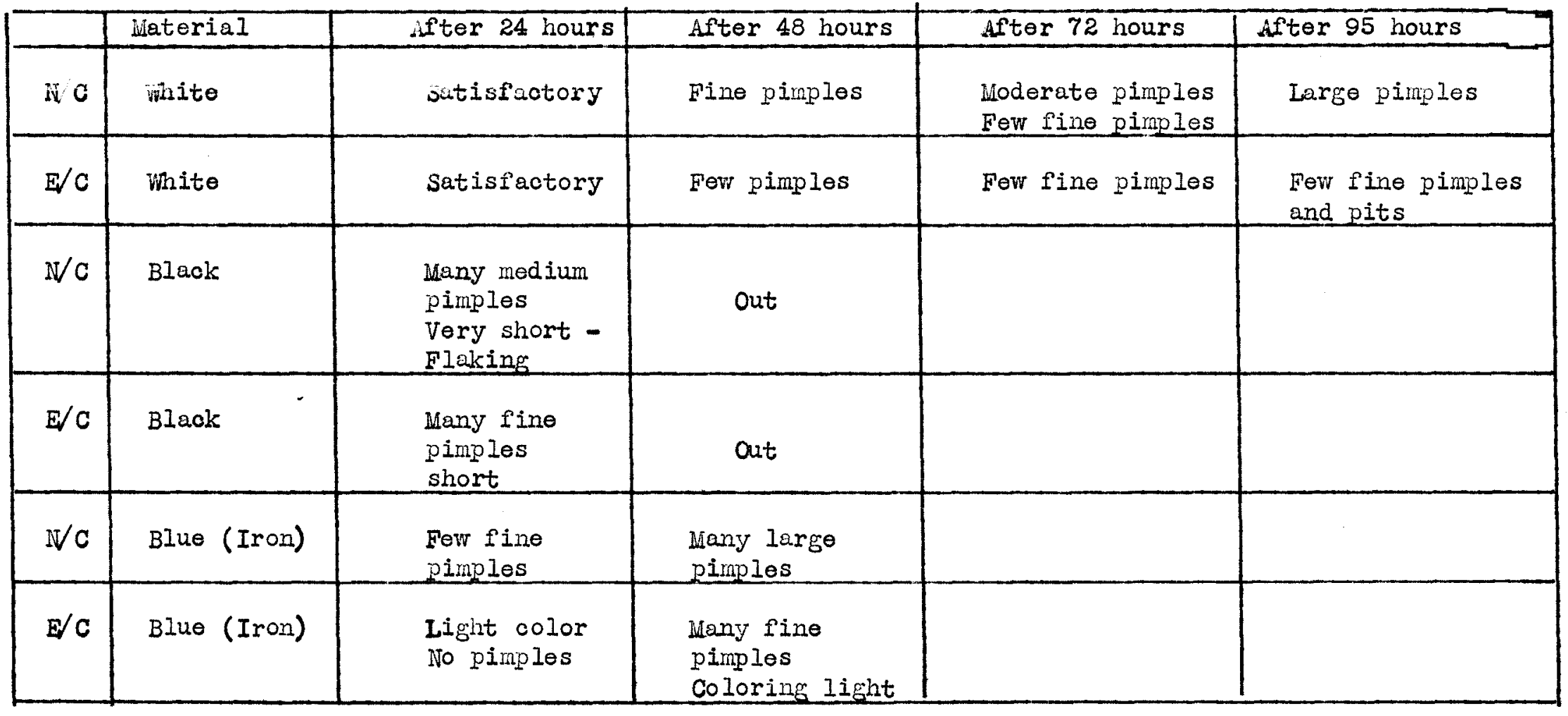

Continued on page 25. 
TABLE V (Continued)

COMPARISON OF NITROCELLULOSE AND ETHYLCELLULOSE FOR WATER SOAK -

AERATED TANK AT $105-110^{\circ} \mathrm{F}$

\begin{tabular}{|c|c|c|c|c|c|}
\hline & Material & After 24 hours & After 48 hours & After 72 hours & After 95 hours \\
\hline $\mathbb{V} C$ & Red (oxide) & Satisfactory & $\begin{array}{l}\text { Few fine } \\
\text { pimples }\end{array}$ & $\begin{array}{l}\text { Many large } \\
\text { pimples }\end{array}$ & Out \\
\hline$E / C$ & Red (Oxide) & Satisfactory & $\begin{array}{l}\text { Dense fine } \\
\text { pimples }\end{array}$ & Out & \\
\hline $\mathbb{W} C$ & Yellow (Chrone) & Satisfectory & $\begin{array}{l}\text { Few fine } \\
\text { pimples }\end{array}$ & $\begin{array}{l}\text { Many fine } \\
\text { pimples }\end{array}$ & $\begin{array}{l}\text { Many fine and } \\
\text { large pimples }\end{array}$ \\
\hline$E / C$ & Yellow (Chrome) & Satisfactory & Satisfactory & Satisfactory & $\begin{array}{l}\text { Satisfaotory } \\
\text { Lost gloss }\end{array}$ \\
\hline$E / C$ & Green (Chrome) & Satisfactory & $\begin{array}{l}\text { Few fino } \\
\text { pimples }\end{array}$ & $\begin{array}{l}\text { Many fine } \\
\text { pimples }\end{array}$ & $\begin{array}{l}\text { Many large \& } \\
\text { fine piuples } \\
\text { No gloss }\end{array}$ \\
\hline$E / C$ & Green (Chrome) & Satisfactory & $\begin{array}{l}\text { O. K. } \\
\text { Light Color }\end{array}$ & $\begin{array}{l}\text { Few fino } \\
\text { pimples. } \\
\text { Very light }\end{array}$ & $\begin{array}{l}\text { Many fine } \\
\text { pimples. } \\
\text { Low gloss }\end{array}$ \\
\hline
\end{tabular}


TABIE VI

RESUITS OF THE COID-CHECK TEST

Ithyl Cellulose Yellow

Ethyl Cellulose White

Nitrocellulose Black

Nitrocellulose White
Extremely bad in 8 cycles

$\mathrm{Bad}$ in 8 cycles

Some cracking on edge at 4 cycles. No further cracking on continued testing.

Noderate, general cracking at 12 cycles.

All others showed no deterioration at 20 cycles when the test was discontinued. 
chrome yellow ethyl cellulose, and to a lesser extent the chrome green ethyl cellulose, showed more darkening than the nitrocellulose. A large percentage of this is due, without a doubt, to the large percentage of phenolic resin in the vehicle, the phenolic being notably poor for yellowing and darkening in ultra violet light or heat. Pigments of different sources or of different types (as, for example, acetate and nitrate base chrome yellows), although having the same chemical composition, have varying degrees of color retention. However, this latter point is of little interest in this work.

The white, green, and chrome yellow ethyl cellulose lacquers in particular show the undesirable property of waterspotting, giving an uneven film surface.

Both ethyl cellulose and nitrocellulose black lacquers show signs of fine pimpling on the edges and corners of the panels. 


\section{CONCLUSIONS AND RECOMMENDATIONS}

These tests indicate that the ethyl cellulose lacquers compare favorably with nitrocellulose lacquers. There are a few disadvantages of the former such as poor water resistance as indicated by whitining on water soak and water spotting in the accelerated weathering machine, darkening caused by high phenolic content, and high cost because of the relatively high cost of the vehicle. However, it is an indication of what may be done with this type of material. Fthyl cellulose is definitely better in regard to flexibility, inflammability, and its non-lifting of undercoats.

Further work might consist of attempts to increase gloss still further. Possibilities here are the use of wetting agents in the dispersion such as zinc napthenate, zinc resinate, ester gum, etc. The use of Bakelite 3180 helps gloss considerably in nitrocellulose lacquers and may help here. The use of dewaxed dammar or shellac would probably improve adhesion and may show to advantage in regard to gloss. Comparsons should also be made with alcohol soluble nitrocellulose since this would be a competitor in regard to cheapness of solvents. Alcohol soluble (Ss) cotton, however, is not considered to have quite the durability of regular (RS) cotton. The work to date has been in simple proportions of 
Ethocel, one plasticizer, and one resin in a given mixture. Frequently better results can be obtained by the use of several resins and plasticers, e.g., phenolic for durability and water resistance, shellac for adhesion and flexibility.

The use of modified phenolic or even cheap resin such as Vinsol (sold by Hercules Power) would do much to decrease the cost. The latter resin has two defets, however, its dark color and its slight bleeding, but its cost of 3 to $3 \frac{1}{2}$ cents per pound makes it look attractive. 
AN ETHYL CELLULOSE IACQUER FOR COATING PIASTICS 


\section{INTRODUCTI ON}

Ethyl cellulose plastics are well known as a thermoplastic molding compound being an ether of ethyl alcohol and cellulose. They are outstanding in toughness and strength, low temperature shock resistance, and retention of original properties on aging or on exposure to a wide range of temperature-humidity conditions. They are available in various forms for extrusion, compression, or injection molding as well as a variety of flow grades.

These plastics will give good gloss if molded with polished dies or if buffed. Variegated effects can also be obtained. However, it is sometimes desirable to coat these plastics with a colored lacquer to hide slight imperfections that may have developed or for letters, numerals, and other designs which may be applied directly or in recessions or depressions for color contrast.

These lacquers or paints must be carefully selected because of the solvent action on the plastic itself, which may cause orange peel, swelling, warping, and other forms of distortion.

It is desired to derelop an ethyl cellulose type lacquer that can be used on thin sections of ethyl cellulose plastic, particularly Ethocel Plastic IT and Ethocel Plastic IR 
manufactured by the Dow Chemical Company of Midland, Michigan.

The lacquer desired should be pale, that is, satisfactory for white or at least for very pale colors. It should not cause distortion or other underirable effects on the plastic, and it should have a high gloss, good hardness, and a durability comparable to the plastic. 


\section{MATERIAIS}

The materials listed below are those used in the second part in addition to those described in the first part on pages $13-14$.

Amberol M-93 - A modified phenolic made by Resinous Products and Chemicals Co., Philadelphia, Penn.

Beckacite 1113 - A modified phenolic, made by Reichold Chemicals Co., Detroit, Mich.

Beckacite 1110 - Haleic modified ester gum supplied by Reichold Chemicals Co.

Amberol 800 - Maleic modified ester gum supplied be Resinous Products and Chemicals Co.

Syntex H-3 - A maleic modified ester gum obtained from Jones-Dabney Co., Louisville, Ky.

Teglac 152, Teglac Z-152, and Teglac 161 - Three maleic modified ester gums produced by American Cyanamid Co., New York City.

Beckosol 1324 - An alkyd solution manufactured by Reichhold Chemicals Co. It is $80 \%$ non-volatile in toluol, weighs 8.35 pounds per gallon, and has an acid value of about 6 .

Amberlac B-94 - Alkyd made by Resinous Products and Chemicals Co. and is $80 \%$ non-volatile in toluol. 
Dow \#6 Plasticizer - Trade name for di o-amyl mono phenyl phosphate manufactured by Dow Chemical Co.. Midland, Michigan.

Shell TS-28 - A petroleum naptha that is primarily aromatic in nature and somewhat similar to xylol. It is distributed by shell oil co.

Solvesso \#l - Another aromatic petroleum naptha but similar to toluol and furnished by standard Oil of New Jersey. 


\section{PREPARATION OF PIGMENTED ILACQUERS}

The first step in the preparation of pigmented lacquers was to obtain a two-roll mill dispersion of the pigment in ethyl cellulose because this method was the most practical of the various methods used to obtain good gloss with this vehicle. A mix of $53.3 \%$ Titanium Dioxide, $38.7 \%$ Ethyl Cellulose, and $8.0 \%$ n-Butanol by weight was made and ground on a differential speed two-roll mill for 15 minutes. The butanol is necessary to get the ethyl cellulose so that the mass will adhere to the roll for a sufficient length of time for the ethyl cellulose to become plastic because of the increase of temperature caused by milling. Because of the volatility of the butanol the composition of the chips is assumed to be:

$$
\begin{array}{lr}
\text { Kreb's R-110 } & 56.7 \% \\
\text { Ethocel, } 7 \text { cps standard Ethoxy } 41.3 \% \\
\text { n-Butanol } & \frac{2 . \%}{100 \%}
\end{array}
$$

This assumption is made on the basis of many similar grinds for industrial application, where titanium dioxide and similar pigments that permit a high pigment to resin ratio will give a chip at $98 \%$ non-volatile; ferrites and similar pigments give chips a $95 \% \mathrm{~N}_{0} \mathrm{~V}_{0}$, and See section on Materials - page 12 
the organic colors, blacks and blues, will yield chips at $92 \% \mathrm{~N} . \mathrm{V}$.

These chips are then blended with the desired amounts of other constituents by placing them in a round pint tin can and tumbling over night. 
DATA AND RESULTS WITH INTERPRETATION

The first formula PI-l (See Table VII) that was developed had excellent flexibility and hardness over a hard surface; but when it was coated on the desired plastics, a soft, mushy, non-drying film resulted. It was evident that the plasticizer of the plastic was bleeding or leaching into the lacquer film. The logical step was then to shorten the film, by cutting down on the plasticizer and increasing the hard resin.

For the preliminary work, hard resin and ethyl cellulose were used without plasticizer. Various hard resins were tried to evaluate their relative merits by formulating formulae PL-2 to PL-7 inclusive.

Two types of unmodified phenolic resins were usedAmberol M-93 and Beckacite 3000, a modified phenolic Beckacite 1113, a maleic modified ester gum syntex $\mathrm{H}-3$, and two natural resins - Congo and undewaxed dammar. Ister gum was not used because of its poor solvent release.

Reduction of these lacquers at a ratio of two volumes of lacquer to one volume of thinner composed of $20 \%$ Butanol, 30\% Xylol, and 50\% solvesso No. I by weight gave a viscosity suitable for application by spray. Two moderate 
TABLE VII

PLASTIC LACQUER FORMULATIONS

\begin{tabular}{|c|c|c|c|c|c|c|c|c|c|c|}
\hline & PImI & PI-2 & PIm 3 & PL-4 & PI 5 & PI 6 & PIn 7 & PI- 8 & PI-9 & PI -10 \\
\hline $\begin{array}{l}\text { \% Plgment } \\
\text { Krebs RT-110 }\end{array}$ & 6.5 & 8.5 & 8.5 & 8.5 & 8.5 & 8.5 & 8.5 & 7.73 & 7.73 & 2.73 \\
\hline $\begin{array}{l}\text { I Ethyl Cellulose } \\
7 \text { ops stdoEthoxy }\end{array}$ & 13.0 & 6.2 & $6 \cdot 2$ & 6.2 & 6.2 & 6.2 & 6.2 & 14.73 & 5.63 & 7.90 \\
\hline $\begin{array}{l}\% \text { Beokacite } \\
3000\end{array}$ & & 31.1 & & & & & & & & \\
\hline $\begin{array}{l}\text { umberol } \\
\text { 1-93 }\end{array}$ & & & 31,1 & & & & & & & \\
\hline $\begin{array}{l}\text { 8eokacite } \\
1113\end{array}$ & & & & 31.1 & & & & & & \\
\hline $\begin{array}{l}\text { \% Syntex } \\
\mathrm{B}=3\end{array}$ & 1.2 & & & & 31.1 & & & & 28.26 & 21.21 \\
\hline$\%$ Congo & & & & & & 31.2 & & & & \\
\hline $\begin{array}{l}\text { Undewaxed } \\
\text { Demmar }\end{array}$ & & & & & & & 31,2 & & & \\
\hline $\begin{array}{l}\% \text { Beokos ol } \\
1324\end{array}$ & 1.7 & & & & & & & & & \\
\hline $\begin{array}{l}\text { Amberlac } \\
\text { B-94 }\end{array}$ & 3.0 & & & & & & & & & \\
\hline $\begin{array}{l}\text { Dow } \\
\text { Plastiolzer } 6\end{array}$ & & & & & & & & 9.10 & 9.10 & 9.10 \\
\hline $\begin{array}{l}\text { Total } \\
\text { Solvent }\end{array}$ & 74,6 & 54.2 & 54.2 & 54.2 & 54.2 & 54.2 & 54.2 & & & \\
\hline Fin-Butanol & & & & & & & & 6.62 & 6.08 & 6.22 \\
\hline $\begin{array}{l}\text { Industrial } \\
\text { xylol }\end{array}$ & & & & & & & & 27.3 & 27.3 & 27.3 \\
\hline$\left[\begin{array}{l}s h \theta 11 \\
T S-28\end{array}\right.$ & & & & & & & & 34.52 & 15.9 & 20.55 \\
\hline
\end{tabular}


passes were applied to the 1/8" thick black plastic discs which were then dried several days and then submitted to accelerated weathering for 50 hours.

The accelerated weathering machine is a National Carbon Company type; Corex $D$. filters were used with Sunshine Carbons.

The results of this test are shown in Table VIII. of the resins tried it is seen that syntex $\mathrm{H}-3$ is among the best, and it is the least expensive. Howerer, the formulation is slightly short. Various other maleic estergum resins were later tried with equal success.

For further work more panels were required, but the second lot was much thinner and softer than the first. Moreover, it was found that on spraying the lacquer on these newer green panels the gloss was not uniform. This is apparently caused by incompatibility of die lubricant with the lacquer.

It was found that polishing with a metallurgical wheel removed the cause and good gloss was then obtainable. To lengthen the lacquer to prevent shortness of film and curling of the thin plastic discs, a series of lacquers was then made using three different plasticizers at various ratios. One, two, four, and ten per cent of dibutyl phthalate, blown castor oil, and Dow No. 6 Plasticizer were added to PI-5. The addition of $4 \%$ of blown castor oil (Baker Castor Oil Co's \#15) gave films that were too soft and mushy, 
RESULTS OF WEATHEROMETER TESTS

\begin{tabular}{|c|c|c|}
\hline Lacquer & Resin & Results after 50 hours \\
\hline $\mathrm{FI}-2$ & Beckacite 3000 & Bad cracking and yellowing \\
\hline $\mathrm{PI}-3$ & Amberol $\mathbb{H}-93$ & $\begin{array}{l}\text { Bad initial cracking; } \\
\text { yellow; low gloss }\end{array}$ \\
\hline $\mathrm{PI}-4$ & Beckacite 1113 & $\begin{array}{l}\text { slight cracking; more } \\
\text { yellow than syntex } \mathrm{H}-3\end{array}$ \\
\hline$P L-5$ & Syntex $\mathrm{H}-3$ & $\begin{array}{l}\text { slight cracking; fairly } \\
\text { good color }\end{array}$ \\
\hline$P L-6$ & Congo & $\begin{array}{l}\text { Initial color yellow; } \\
\text { loss of gloss }\end{array}$ \\
\hline PL-7 & Undewaxed Dammar & $\begin{array}{l}\text { Very bad cracking; loss } \\
\text { of gloss }\end{array}$ \\
\hline
\end{tabular}


but $4 \%$ of the two chemical plasticizers was still not sufficient to prevent curling. But 10\% Dow P-6 did give a nice looking panel having good hardness and a minimum amount of curling. However, when placed in the weathering machine extremely bad cracking and checking occurred. Without doubt, this si caused by the low ratio of thyl cellulose to hard resin, giving little film strength.

Two lacquers were then made, one the same as used above, namely PI-5 plus $10 \%$ Dow P-6, the other being similar but using straight ethyl cellulose. These are PI-8 and PI-9. These two lacquers were then blended in ratios of three to one, one to one, and one to three, reduced and sprayed on the thin green plastics using Lacquer PL- 6 as the standard. After 60 hours in the accelerated weathering machine, Formula PI-9 cracked and curled badly. The others were in good shape except for increasingly lower gloss for higher ratios of ethyl cellulose. This, together with the higher cost angle, would indicate that the one to three ratio is about the optimum, and was given number PI-10.

As mentioned above, to obtain good gloss it was assumed necessary to polish the initial green panels on a metallurgical wheel using a duck cloth wheel with an aqueous alumina suspension as the abrasive. This would be rather difficult in industrial practice so that a series was made using various cleaning methods having an unpolished disk as standard. 
Unexpectedly, all trouble with flat or low gloss spots disappeared, This is probably the result of the increased ethyl content, the die lubricant or plasticizer being more compatible with ethyl cellulose than with the hard resin.

To obtain alternates for syntex $\mathrm{H}-3$, several other maleic-ester gum resins were substituted, namely Amberol 800 , Teglac 152, Teglac Z-152, Teglac 161, and Beckacite 1110. Amberol 800 was very poor giving a wrinkled appearance. Beckacite 1110 originally looked fairly good, but on exposure to ultraviolet light it tended to wrinkle. All three Teglac resins worked quite successfully.

To lower the cost of the lacquer and also to decrease still further the curling tendency of the panels when placed in the accelerated weathering machine, several formulations were made using Vu\&P naphtha for various portions of the $x y l o l$ and reducing the amount of alcohol.

It was found that reducing the amount of butanol caused the reappearance of pin holes and further reduction resulted in a solvent too weak to dissolve the ethyl cellulose. However, replacement of $x y l o l$ with VM \& $P$ worked successfully. To check the curling tendency of the lacquer, coated panels together with an uncoated panel were then placed in the weatherometer. The results showed that the bare panel warped as badly as if not worse than the lacquered panel. This showed that heat had more influence on the warping of the panels than 
the solvent present in the lacquer. Further increase of Dow No. 6 Plasticizer resulted in only softer films, and because of its high cost, a return to the $9.1 \%$ figure was made. 
CONCLUSIONS AND RECOMMENDATIONS

Hence a completed formula for a pale, durable lacquer for the plastic would be:

$\begin{array}{lr}\text { Kreb's RT-110 } & \text { ) Two } \\ 7 \text { cps Ethocel (Std. Ethoxy) } \begin{array}{cr}\text { roll } \\ \text { mill } \\ \text { chip }\end{array} & \frac{0.72 \%}{13.62 \%} \\ \text { n-Butanol } & 2.63 \% \\ 7 \text { cps Ethocel (Std. Ethoxy) } & 21.21 \% \\ \text { Syntex H-3 } & 9.1 \% \\ \text { Dow Plasticizer No. 6 } & 5.95 \% \\ \text { n-Butanol } & 27.3 \% \\ \text { V.H. \& P Naphtha } & \frac{20.55 \%}{100.00 \%} \\ \text { Shell TS-28 } & \end{array}$

This is, of course, a white which may be tinted to any of the pastel shades. If other colors are desired, substitution of appropriate dispersions should work equally well. A reduction of two volumes of lacquer to one volume of thinner composed of $20 \%$ n-Butanol, $30 \%$ industrial Xylol, and $50 \%$ Solvesso No. I gives a viscosity suitable for spraying. High amounts of butanol are required to prevent skin drying and subsequent pinholing. This latter trouble was very great in our initial panels using ethanol for the activating solvent. For brush application it is suggested that a slower aromatic-solvent be used, e.g., high-flash naphtha or solvesso $30 / 40$. 


\section{IITERATURE CITED}

1. Ameican Gum Importers Handbook, "Natural Resin Handbook" (1939).

2. Denham, 麗, and Woodhouse, H.; J. Chem. Soc. 103, 1735 (1913); 105, 2357 (1914).

3. Dow Chemical Co., Industrial Fublication, "Ethocel" (Dow Ethyl Cellulose) (1940).

4. Dow Chemical., Industrial Publication, "Plastic Materials and Plasticizers". (1942).

5. Dreyfus, H., British Patent 462,272 (March 5, 1937).

6. Ernst, R. C., University of Louisville, Private communication. (1942).

7. Hercules Powder Co.. Industrial Publication, "Ethyl Cellulose (1944).

8. Koch, W., Ind. Eng. Chem., 29, 687 (1937).

9. Leuchs, 0., German Patent 322,586 (July 1, 1920).

10. Lilienfeld, L., British Patent 6035 (1913).

11. Mattiello, J. J., "Protective and Decorative Coatings", Vol. III, Chapter 23, (1943). John Wiley.

12. Suida, W., Monatsh., 26, 413 (1905).

13. Van Heuckeroth, A. W., (National Paint, Varnish, and Lacquer Association, Inc.) Scientific Section Circular No. 545 (1937). 


\section{ACKNOWIEDGEMENTS}

This research was made possible by a research grant of the Dow Chemical Company of Midland, Michigan. The problems were suggested by the Cellulose and Plastics Division of this company. The author wishes to express his sincere appreciation and gratitude to the Dow Chemical Company and to its employees, in particular $\mathrm{Hr}$. A. F. Young, for the invaluable assistance and guidance that has been rendered.

The author also wishes to acknowledge the helpful laboratory assistance of Walter Zabban, Charles Sacra, and Wilbur Adams. 